Conclusion Elevated $\mathrm{Na}$ leads to complex metabolic alterations preceding any energetic and functional impairment. Early prevention of $\mathrm{Na}$ overload and inhibition of $\mathrm{Na} / \mathrm{Ca}_{\text {mito }}$ could ameliorate metabolic dysregulation in hypertrophy and failure.

\section{P2 $\quad$ FATTY ACID TRANSPORTER1 (FAT/CD36) AND GUANINE NUCLEOTIDE-BINDING PROTEIN G(I) SUBUNIT ALPHA-2 (GALPHAI2) ARE NOVEL SUBSTRATES OF THE CELL SURFACE LOCALISED PALMITOYL TRANSFERASE DHHC5}

Fiona Plain, Niall J Fraser, Will Fuller. Division of Molecular and Clinical Medicine, University of Dundee

\subsection{6/heartjnl-2018-BSCR.7}

Palmitoylation is the reversible addition of a 16 carbon fatty acid group to cysteine residues on proteins. The forward reaction is catalysed by DHHC palmitoyl acyl transferase (PAT) enzymes and there are 23 human isoforms. DHHC5 is a cell surface localised PAT proposed to contribute to cardiac reperfusion injury. A peptide array based on the DHHC5 extended C tail was used to screen rat cardiac lysates for DHHC5 interactors, which were subsequently identified by mass spectrometry. Biotinylated peptides covering the C-tail of DHHC5 were incubated with cardiac lysates and captured on streptavidin sepharose beads. Following the removal of contaminants, targets were identified as potential substrates of DHHC5 if they appear in the cardiac palmitoyl proteome or the SwissPalm database. Included are several kinases, phosphatases, ion transporters, G protein alpha subunits (Galphai2) as well as GLUT4 and FAT/CD36. DHHC5 interactors identified in the screen were expressed with an $\mathrm{N}$ terminal GFP tag for detection in both HEK293 and Crispr-engineered FT293 DHHC5 $\mathrm{KO}$ cells. Acyl resin assisted capture (AcylRAC) was used to assess their palmitoylation. Both FAT/CD36 and Galphai2 were less palmitoylated in DHHC5 KO cells, and this was restored on over expression of DHHC5 (but not DHHC17), indicating these are DHHC5 substrates. Further work will investigate the functional consequences of DHHC5 palmitoylation of CD36 and Galphai2, as well as validating other putative DHHC5 candidate substrates.

\section{P3 CROSSTALK BETWEEN GLUCOSE AND CREATINE IN THE HEART}

HJ Whittington, HA Lake, C Antoniades, S Neubauer, CA Lygate, S Zervou*. Division of Cardiovascular Medicine, Radcliffe Department of Medicine, University of Oxford, Oxford

\subsection{6/heartjnl-2018-BSCR.8}

Background Diabetic cardiomyopathy is characterised by metabolic remodelling, impaired glucose and high-energy phosphate metabolism. Transgenic mice overexpressing the creatine transporter in the heart (CrT-OE) have high intracellular creatine and elevated glucose, suggesting changes in substrate utilisation.

Objective We aimed at investigating the unexplored glucosecreatine link, in addition to the involvement of shared molecules in glucose and creatine metabolism.
Methods and results The correlation between myocardial creatine and glucose $(\mathrm{r} 2=0.67 ; \mathrm{p}=0.002)$ is accompanied by increased Glucose transporter 4 (Glut4) $(\mathrm{p}<0.05)$ and sodiumglucose co-transporter SGLT1 gene expression. Thioredoxin interacting protein (Txnip), that inhibits glucose and creatine transport (via Glut4 and CrT, respectively) is elevated in CrTOE $(p<0.05)$, indicating activation of both metabolic pathways.

To test if modulating creatine in vivo alters glucose uptake, we measured 3H-2-deoxyglucose incorporation in isolated cardiomyocytes from CrT-OE and WT hearts. In WT, insulin caused a 2-fold increase $(\mathrm{p}<0.05)$ in glucose uptake, unaffected by exogenous creatine pre-exposure. CrT-OE cells showed blunted glucose uptake vs WT in response to insulin $(\mathrm{p}>0.05)$ and responded to creatine $(\mathrm{p}<0.01)$.

In a cohort of samples taken during coronary artery bypass surgery from diabetic and non-diabetic patients $(n=8$ each; blood glucose $90 \pm 7.1$ and $138 \pm 16.5$, respectively), there was a negative correlation between $\mathrm{CrT}$ and Glut4 transcript $(\mathrm{r} 2=-0.5 ; \mathrm{p}=0.028)$ further supporting the glucose-creatine relationship in the clinical setting.

Conclusion Our observations suggest that changing myocardial creatine can regulate glucose uptake. Further studies will explore the potential use of creatine as a biochemical 'switch' to correct impaired glucose uptake and potentially insulin resistance.

\section{P4 $\alpha$-TOCOPHEROL DOES NOT INHIBIT LOW DESNSITY LIPOPROTEIN OXIDATION AT LYSOSOMAL PH}

HKM Alboaklah*, DS Leake. University of Reading

\subsection{6/heartjnl-2018-BSCR.9}

The oxidation of low density lipoprotein (LDL) was considered to be important in atherogenesis. It is well known that $\alpha$-tocopherol protects against the oxidation of LDL by cells or copper ions, but $\alpha$-tocopherol did not protect against cardiovascular disease in large clinical trials, leading some to doubt the importance of oxidised LDL. We have previously shown that LDL is oxidised in the lysosomes of macrophages, due to their acidic $\mathrm{pH}$ and presence of redox-active iron, raising the possibility that this is the main site of LDL oxidation, rather than the extracellular space of the arterial intima. We have now enriched LDL with $\alpha$-tocopherol (by adding $\alpha$-tocopherol to human plasma followed by the isolation of LDL by ultracentrifugation) and measured its oxidation by monitoring conjugated diene formation in a spectrophotometer set to $37^{\circ} \mathrm{C}$ and $234 \mathrm{~nm}$. $\alpha$-Tocopherol-enriched LDL was oxidised much slower by $\mathrm{Cu} 2+(2,5$ or $20 \mu \mathrm{M})$ at $\mathrm{pH} 7.4$, as expected, but was not protected against oxidation by these concentrations of $\mathrm{Cu} 2+, \mathrm{Fe} 2+$ or $\mathrm{Fe} 3+$ at $\mathrm{pH} 4.5$ (lysosomal pH). The lack of protection of cardiovascular disease by $\alpha$-tocopherol is therefore not proof that oxidised LDL is not important in atherosclerosis, if the oxidation of LDL occurs in lysosomes. We therefore need to retest the oxidised LDL hypothesis using antioxidatnts that accumulate in lysosomes and inhibit the oxidation of LDL at acidic $\mathrm{pH}$.

We thank the Iraqi Government for a $\mathrm{PhD}$ studentship (HKMA). 